\title{
Two-Phase Hybrid Forward Convertor with Series-Parallel Auto-Regulated Transformer Windings and a Common Output Inductor
}

\author{
Xinke $\mathrm{Wu}^{\dagger}$ and Hui Chen ${ }^{*}$ \\ $\dagger^{*}$ College of Electrical Engineering, Zhejiang University, Hangzhou, China
}

\begin{abstract}
For conventional interleaved two-phase forward converters with a common output inductor, the maximum duty cycle is 0.5 , which limits the voltage range and increases the difficulty of the transformer's optimization. A new two-phase hybrid forward converter with series-parallel auto-regulated transformer windings is presented in this paper. With interleaved control signals for the two phases, the secondary windings of the transformers can work in series when the duty cycle is larger than 0.5 , and they can work in parallel when duty cycle is lower than 0.5 . Therefore, the maximum duty cycle is extended and the turns ratio of the transformer can be optimized. Duty cycle dependent auto-regulated windings result in the steady states of the converter being different in different duty cycle ranges $(\mathrm{D}>0.5$ and $\mathrm{D}<0.5)$. Fortunately, the steady state gains of the proposed hybrid converter are identical at different duty cycle ranges, which means a stepless shift between two states. A prototype is built to verify the theoretical analysis. A conventional control loop is compatible for the whole input voltage range and load range thanks to the stepless shifting between the different duty cycle ranges.
\end{abstract}

Key words: Common output inductor, DC-DC, Forward, Series-parallel auto-regulated, Two-phase interleaving

\section{INTRODUCTION}

Hybrid converters have become attractive in recent years because of their distributed power dissipation, better thermal management, and low current or voltage stresses [1]-[16]. Papers [1]-[3] proposed hybrid dc-dc converters with hybrid bridge rectifiers. Their secondary side windings can be auto-regulated according to the duty cycles and phase-shift angle between the two phases. In addition, some combining methods have been proposed for hybrid converters [4]-[6]. However, these combining methods are not suitable for Half-Wave Rectifiers (HWR), which are combined with forward topologies. The forward converters have attracted some attention in that they have less components and simple control [7]-[22]. Literature [12] provided a comprehensive

Manuscript received Feb. 21, 2013; revised May 21, 2013

Recommended for publication by Associate Editor Honnyong Cha.

†Corresponding Author: wuxinke@zju.edu.cn

Tel: +86-571-87952224, Zhejiang University

${ }^{*}$ College of Electrical Engineering, Zhejiang University, China comparison between a parallel hybrid forward converter with one output inductor and the conventional two-phase interleaved forward converter for dc-dc telecom power conversion applications. They have almost identical conduction losses and power density. However, the duty cycle of the parallel hybrid forward converter must be less than 0.5 even with the active clamp structure in Fig. 1(a), which limits its application [13]. With the stacked rectifying structure for hybrid forward converters and the active-clamp technique [14], the duty cycle can also be extended to higher than 0.5 . Obviously, with the stack rectifier, the secondary conduction loss increases. In order to extend the effective duty cycle, the two-phase hybrid active-clamp forward converter shown in Fig.1(b) was proposed in [15]. In the proposed hybrid forward converter, a diode, $\mathrm{D}_{2}$, is added based on the parallel hybrid rectifier. The operating principle including the switching transitions of the hybrid forward converter has been introduced in [15]. This paper emphasizes the design considerations for the key components and implementation of the proposed forward converter for $\mathrm{dc}-\mathrm{dc}$ telecom power supply applications. 


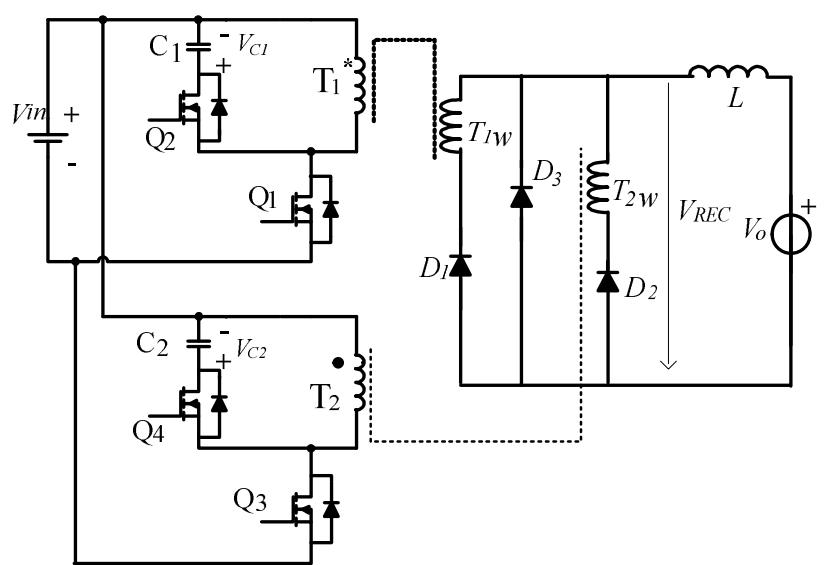

(a) Parallel rectifier.

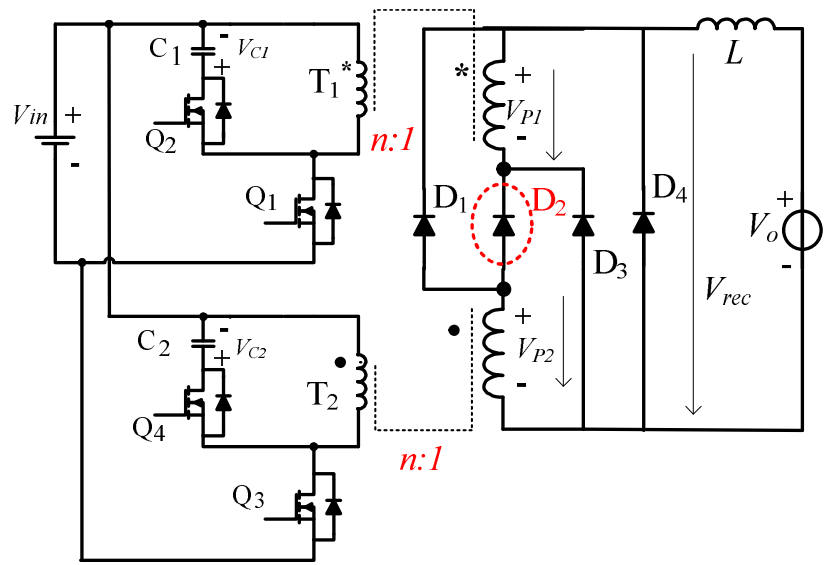

(b) Proposed hybrid rectifier.

Fig. 1. Two-phase hybrid active-clamp forward converters with common output inductor.

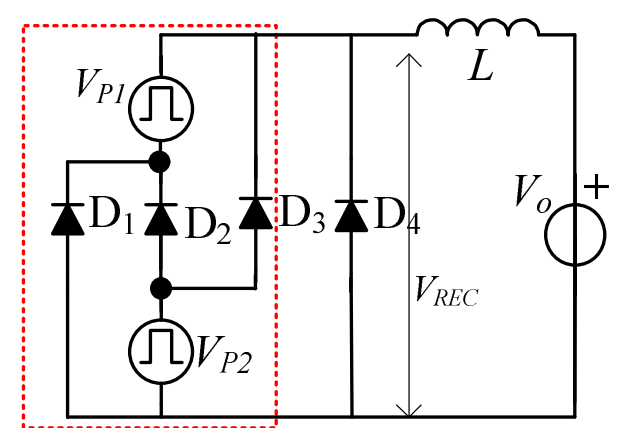

Fig. 2. Simplified two-phase hybrid rectifier.

\section{OPERATING PRINCIPLE OF A TWO-PHASE INTERLEAVED FORWARD CONVERTER WITH THE PROPOSED HYBRID RECTIFIER}

The fundamental operating principle of the proposed converter is briefly presented here, and the stresses in the converter are synthesized and a comparison is made between the parallel hybrid forward converters and the proposed hybrid forward converter. In order to simplify the analysis, the voltages across the secondary side windings are assumed to be $\mathrm{V}_{\mathrm{P} 1}$ and $\mathrm{V}_{\mathrm{P} 2}$, and the high frequency transformers are assumed to be the high frequency pulse voltage sources

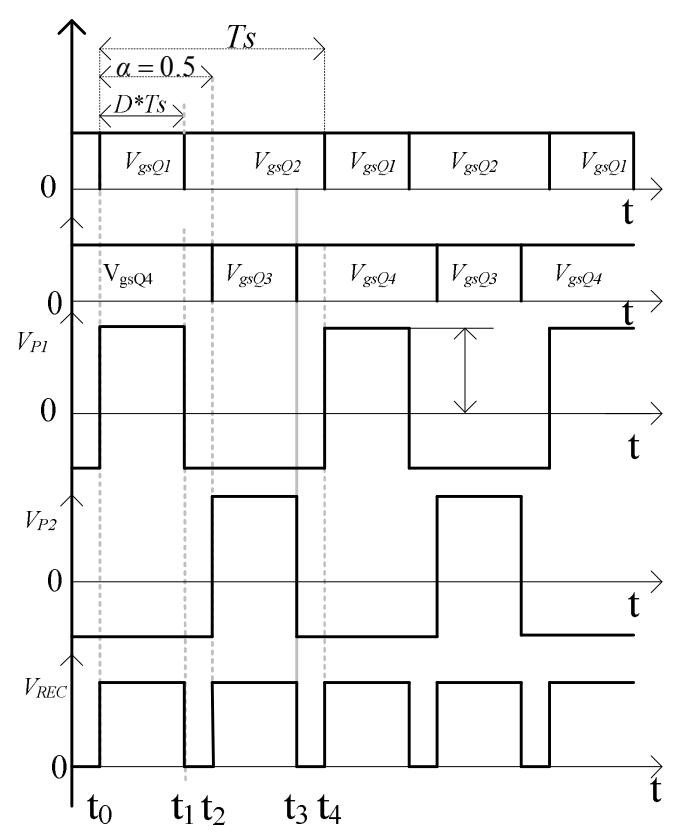

Fig. 3. Interleaving operation of the hybrid rectifier when $\mathrm{D}<0.5$.

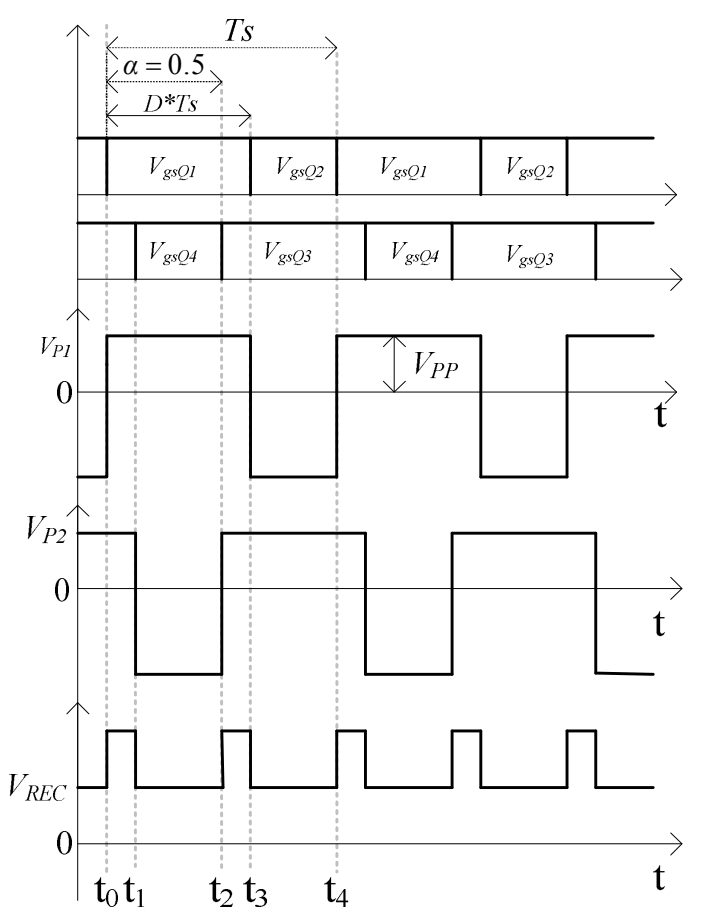

Fig. 4. Interleaving operation of the hybrid rectifier when $\mathrm{D}>0.5$.

shown in Fig. 2.

According to the simplified equivalent rectifying circuits in Fig. 2, the operating principle of the proposed converter with the hybrid rectifier is simplified. Fig. 3 and Fig. 4 show the drive signals and key waveforms of the proposed converter at different duty cycle ranges $(\mathrm{D}<0.5$ and $\mathrm{D}>0.5)$. The operating period in one switching cycle of the hybrid rectifier can be divided into four intervals regardless of 
whether the duty cycles of $\mathrm{V}_{\mathrm{P} 1}$ and $\mathrm{V}_{\mathrm{P} 2}$ are lower than 0.5 or higher than 0.5 . The phase-shift angle between the two phases is $\alpha$, which also represents the phase-shift angle between $V_{P 1}$ and $V_{P 2}$.

\section{Case $1(D<0.5)$}

The phase shift angle between the two phases is 180 degrees and it is defined as $\alpha(\alpha=0.5) . \mathrm{T}_{\mathrm{s}}$ is the switching period. It is assumed that the output inductance is large enough and the current ripple is neglected in the following analysis. The output voltage is Vo. Equivalent circuits of different intervals in one switching cycle when the duty cycle $\mathrm{D}<0.5$ are shown in Fig.5.

Stage $1\left(\mathbf{t}_{\mathbf{0}}-\mathbf{t}_{\mathbf{1}}\right)$ : At $\mathrm{t}_{0}, \mathrm{~V}_{\mathrm{P} 1}$ is positive and $\mathrm{V}_{\mathrm{P} 2}$ is negative. Hence, $D_{1}$ is on and $D_{2}, D_{3}$ and $D_{4}$ are all off. The output voltage of rectifier $\mathrm{V}_{\mathrm{REC}}$ is equal to $\mathrm{V}_{\mathrm{P} 1}$ in this interval. It charges filter inductor $\mathrm{L}$ in this interval.

Stage $2\left(\mathbf{t}_{\mathbf{1}}-\mathbf{t}_{\mathbf{2}}\right)$ : At $\mathrm{t}_{1}, \mathrm{~V}_{\mathrm{P} 1}$ becomes negative and the freewheeling diode $\mathrm{D}_{4}$ conducts. The other diodes are off. If the voltage drop of the diode is neglected, $\mathrm{V}_{\mathrm{REC}}$ is almost zero in this interval. Inductor $\mathrm{L}$ is discharged by Vo.

Stage $3\left(t_{2}-t_{3}\right)$ : At $t_{2}, V_{P 2}$ becomes positive. $D_{4}$ turns off and $D_{3}$ begins conducting after $t_{2}$. Therefore, $V_{P 1}$ begins to charge inductor $\mathrm{L}$.

Stage $4\left(\mathbf{t}_{3}-\mathbf{t}_{\mathbf{4}}\right)$ : After $t_{3}, V_{P 2}$ becomes negative and diode $D_{3}$ is reversed off. The freewheeling diode $\mathrm{D}_{4}$ begins conducting after $t_{3}$. The equivalent circuit of this interval is the same as that of stage 2 because of its interleaving inputs and symmetric duty cycle.

After $t_{4}$, the operating stage is identical to Stage1, and another period begins.

According to the volt-second balance of inductor $\mathrm{L}$ in one switching cycle, the steady state gain of the proposed rectifier can be derived in (1) and (2). It is assumed that the peak value $\mathrm{V}_{\mathrm{PP}}$ and duty cycle $\mathrm{D}$ of two input sources are both identical.

$$
\begin{gathered}
\left(V_{P P}-V_{O}\right) \cdot D \cdot T S=V_{O} \cdot(0.5-D) \cdot T S \\
V_{O} / V_{P P}=2 \cdot D
\end{gathered}
$$

\section{Case 2 (D>0.5)}

The equivalent circuits of the different stages when $\mathrm{D}>0.5$ are shown in Fig.6.

Stage $1\left(t_{0}-t_{1}\right)$ : At $t_{0}, V_{P 1}$ and $V_{P 2}$ are positive, $D_{2}$ is on and $\mathrm{D}_{1}, \mathrm{D}_{3}$ and $\mathrm{D}_{4}$ are off. Hence, $\mathrm{V}_{\mathrm{P} 1}$ and $\mathrm{V}_{\mathrm{P} 2}$ are in stacking in this stage. Voltage $\mathrm{V}_{\mathrm{REC}}$ is $\left(\mathrm{V}_{\mathrm{P} 1}+\mathrm{V}_{\mathrm{P} 2}\right)$, and it charges $\mathrm{L}$ in this interval.

Stage $2\left(t_{1}-t_{2}\right)$ : At $t_{1}, V_{P 2}$ becomes negative, then $D_{2}$ is reversed off and diode $\mathrm{D}_{1}$ begins to conduct. The other diodes are off. $\mathrm{V}_{\mathrm{REC}}$ is equal to $\mathrm{V}_{\mathrm{P} 2}$ in this interval. Inductor $\mathrm{L}$ is discharged by Vo.

Stage $3\left(t_{2}-t_{3}\right)$ : At $t_{2}, V_{P 2}$ becomes positive again. Then $D_{1}$ is turned off and $D_{2}$ begins conducting after $t_{2}$. Therefore, $V_{P 1}$

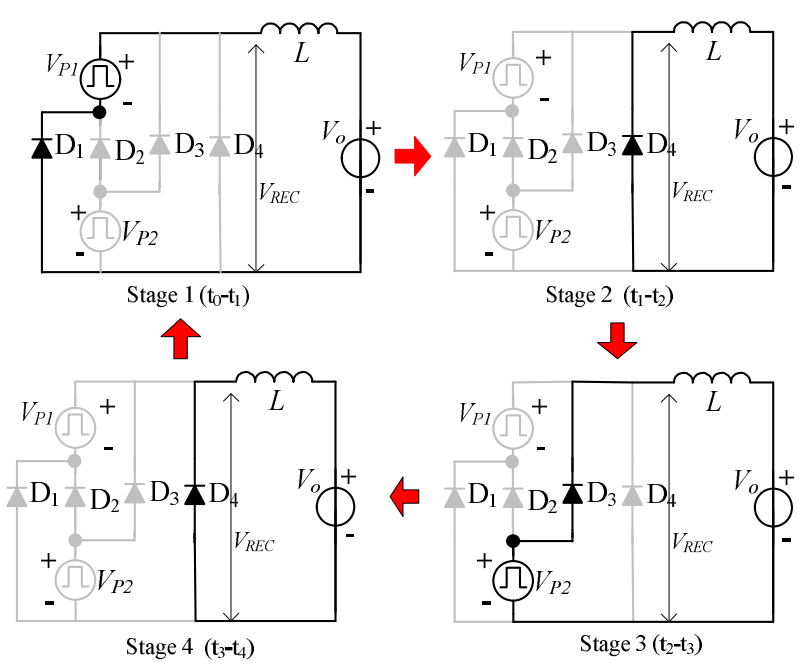

Fig. 5. Equivalent circuits of the proposed hybrid rectifying circuit when $\mathrm{D}<0.5$.

and $V_{P 2}$ are in series again after $t_{2} . V_{R E C}$ is the sum of $V_{P 1}$ and $\mathrm{V}_{\mathrm{P} 2}$, and it begins to charge $\mathrm{L}$.

Stage $4\left(\mathbf{t}_{3}-\mathbf{t}_{\mathbf{4}}\right)$ : After $t_{3}, V_{P 1}$ becomes negative, diode $D_{2}$ is reversed off, and $D_{3}$ begins to conduct. The equivalent circuit of this interval is the same as that in stage 2 because of its interleaving inputs and symmetric pulse width.

After $t_{4}$, the operating stage is identical to Stage 1 , and another period begins.

According to the volt-second balance in one switching cycle of inductor $\mathrm{L}$, the steady state transfer gain of the rectifier can be derived in (3) and (4).

$$
\begin{aligned}
\left(2 V_{P P}-V_{O}\right) \cdot(0.5-(1-D)) \cdot T S & =\left(V_{O}-V_{P P}\right) \cdot(1-D) \cdot T S \\
\frac{V_{O}}{V_{P P}} & =2 \cdot D
\end{aligned}
$$

It is interesting that the steady state gains of the proposed two-phase forward converter in the two duty cycle ranges are the same. This characteristic means that there is no steady state gain transition in whole input voltage range, which avoids large output voltage overshoots or drops. From the equivalent circuits of the operating modes, it is observed that the duty cycle determines the converter's operating condition, namely, series or parallel. There is no current in $\mathrm{D}_{2}$ when the duty cycle is less than 0.5 . When the duty cycle is larger than 0.5 , diode $\mathrm{D}_{2}$ conducts. Hence the duty cycle of the currents in diodes $\mathrm{D}_{1}$ and $\mathrm{D}_{3}$ are limited to 0.5 . The peak current value in the secondary side components for both of the duty cycle ranges is determined by the load current because of the existence of the output filter inductance.

\section{DESIGN CONSIDERATIONS OF AN INTERLEAVED FORWARD CONVERTER WITH THE PROPOSED HYBRID RECTIFIER}

A Duty Cycle and Turn Ratio of the Transformer 


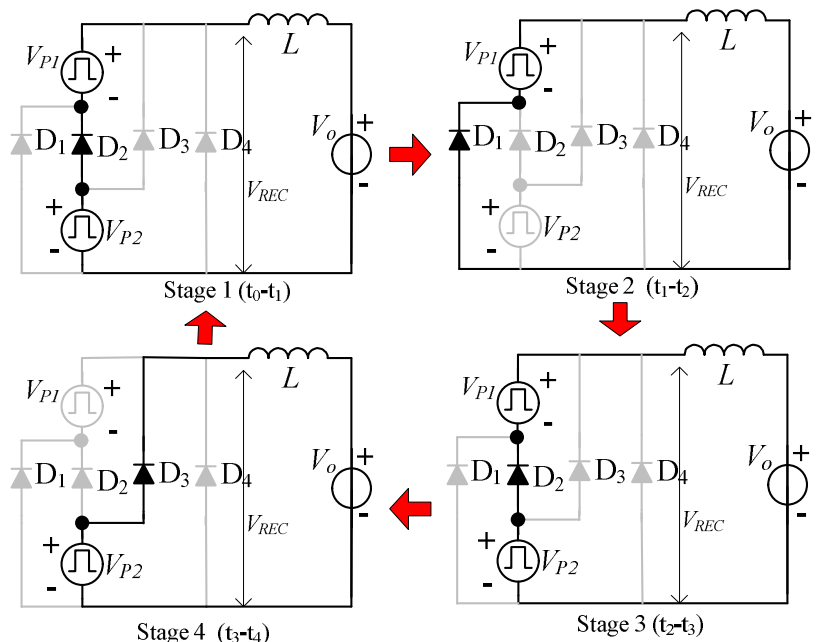

Fig. 6. Equivalent circuits of the proposed hybrid rectifying circuit when $\mathrm{D}>0.5$.

For the parallel hybrid converter, the duty cycle of $\mathrm{V}_{\mathrm{P} 1}$ and $V_{P 2}$ cannot be higher than 0.5 . This limits the input voltage range in dc-dc applications. From the steady state analysis of the proposed hybrid converter, when the duty cycle is higher than 0.5 , the input voltage sources $V_{P 1}$ and $V_{P 2}$ are in stacking in some intervals during one switching cycle. When $\mathrm{D}<0.5, \mathrm{~V}_{\mathrm{P} 1}$ and $\mathrm{V}_{\mathrm{P} 2}$ are in parallel and alternative working state during one whole switch period. It is obvious that the effective duty cycle is much larger and the steady state transfer gain is higher than that of the parallel hybrid rectifier.

Since the switching transition intervals are much less than the on time and off time in one switching cycle, they can be neglected in analyzing the DC characteristics of the proposed convertor. According to Fig. 5 and Fig. 6 and equations (2) and (4), the steady state gain of the converter in Fig.1(b) can be formulated as (5) by replacing $V_{P P}$ with $V_{i n} / \mathrm{n}$. The steady state gains of the parallel hybrid forward converter and the stacking hybrid converter are the same as (5) because the parallel hybrid forward converter is the same as case 1 of the proposed converter and the $V_{R E C}$ of the stacking hybrid converter is the same as that of the proposed converter.

$$
\frac{V_{o}}{V_{\text {in }}}=\frac{2 D}{n}
$$

where $\mathrm{D}$ is the duty cycle of the main switch and $\mathrm{n}\left(\mathrm{n}=\mathrm{N}_{\mathrm{p}} / \mathrm{N}_{\mathrm{s}}\right)$ is the turns ratio of the transformer.

Hence the turns ratio of the transformer can be derived if the output voltage and maximum duty cycle are defined.

$$
n=\frac{2 V_{\text {in_min }_{-}} D_{\text {max }}}{V_{o}}
$$

where $V_{\text {in_min }}$ is the minimum input voltage.

With a larger $D_{\max }$, the turns ratio of the proposed hybrid

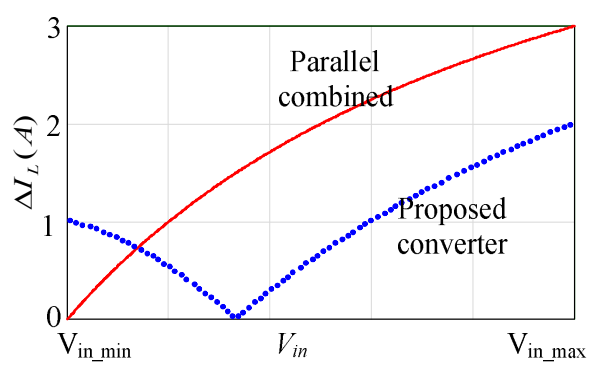

Fig. 7. Current ripples of the proposed hybrid forward converter and the parallel hybrid converter $(\mathrm{Vo}=12 \mathrm{~V}, \quad \mathrm{~L}=30 \mathrm{uH}$, $\left.\mathrm{V}_{\text {in_min }}=36 \mathrm{~V}, \mathrm{~V}_{\text {in_max }}=72 \mathrm{~V}, \mathrm{Ts}=10 \mathrm{us}\right)$.

forward converter is larger than that of the parallel hybrid converter at the same input and output. In addition, it reduces the primary side currents and the primary conduction loss. The current stress of the proposed converter is lower than that of the parallel hybrid converter, and the coefficient of utilization of the core of the transformer is larger.

Since the maximum duty cycle of the proposed hybrid converter is larger than 0.5 , its turns ratio is less than that of a parallel hybrid converter with the same output and input voltage. For instance, when the maximum input versus the minimum input is $2\left(V_{\text {in } \max } / V_{\text {in } \min }=2\right)$, the duty cycle of the two-phase parallel hybrid structure is $0.25-0.5$. Meanwhile, for the proposed structure, the duty cycle range is about 0.33-0.66. Therefore, the turns ratio of the proposed converter can be less than that of the parallel hybrid converter, which also leads to less conduction loss of primary side.

\section{B. Output Current Ripples}

Because of the interleaving control, the effective frequency on the output inductor is double the frequency of the switches. The current ripple of the parallel hybrid forward converter is described in (7). Equation (8) shows the current ripple of the proposed hybrid rectifier with two intervals divided according to the input voltages range corresponding to case 1 and case 2 . In order to make the comparison clear, the key variables of equations (7) and (8) are both the input voltage $V_{\text {in }}$ in that the input voltages are the same for different converters and the duty cycles and turn ratios are different. According to (7) and (8), the ripples between the two schemes are plotted in Fig.7.

$$
\Delta I_{L_{-} p}=\frac{T_{S} \cdot V_{O}}{L}(0.5-D)=\frac{T_{S} \cdot V_{O}}{L}\left(0.5-\frac{n_{1} \cdot V_{O}}{2 \cdot V_{\text {in }}}\right)
$$

where $\mathrm{n}_{1}$ is the turn ratio of the transformer for the parallel hybrid forward converter.

$$
\Delta I_{L_{-} H}= \begin{cases}\frac{T_{S} \cdot V_{O}}{L}\left(0.5-\frac{n \cdot V_{O}}{2 \cdot V_{\text {in }}}\right) & \text { if }\left(n \cdot V_{O} \leq V_{\text {in }} \leq V_{\text {in } \max }\right) \\ \frac{T_{S} \cdot V_{O}}{L}\left(1-\frac{V_{\text {in }}}{n \cdot V_{O}}\right)\left(1-\frac{n \cdot V_{O}}{2 \cdot V_{\text {in }}}\right) & \text { if }\left(V_{\text {in }_{-} \min } \leq V_{\text {in }}<n \cdot V_{O}\right)\end{cases}
$$




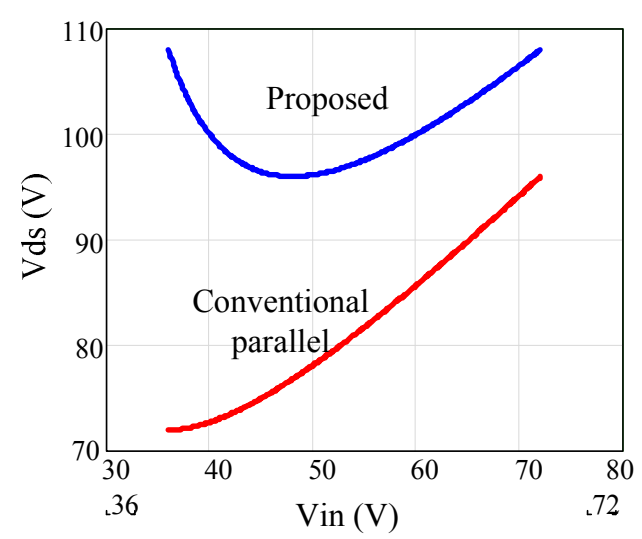

Fig. 8. Primary voltage stresses of proposed converter and parallel hybrid converter.

\section{Voltage Stresses of the Switches}

The primary voltage stresses for the switches are determined by the duty cycle like the conventional active clamp forward converter. According to the volt-second balance of the transformer winding $\left(D^{*} \mathrm{~V}_{\text {in }}=V_{C} *(1-D)\right)$, a general description of $\mathrm{V}_{\mathrm{C} 1}$ and $\mathrm{V}_{\mathrm{C} 2}$ can be derived in (9). For the converters in Fig. 1, voltages $\mathrm{V}_{\mathrm{C} 1}$ and $\mathrm{V}_{\mathrm{C} 2}$ of clamping capacitors $C_{1}$ and $C_{2}$ are assumed to be the same because their duty cycles are almost the same and $\mathrm{V}_{\mathrm{Cl}}=\mathrm{V}_{\mathrm{C} 2}=\mathrm{V}_{\mathrm{C}}$. With different turns ratios, $\mathrm{n}_{1}$ for the parallel hybrid converter and $\mathrm{n}$ for the proposed converter, the voltage stresses for the switches of the converters are derived in (10) and (11), respectively. $\mathrm{V}_{\mathrm{S}-\mathrm{H}}$ represents the voltage stress of the proposed hybrid converter and $\mathrm{V}_{\mathrm{S}-\mathrm{P}}$ represents the voltage stress of the parallel hybrid converter. Fig. 8 shows that the voltage stress of the proposed converter is a bit higher $(10 \%)$ than that of the parallel hybrid converter. However, its effect is low on selecting the switches. For the stacking hybrid forward converter, the voltage stresses of the primary switches are identical to the proposed hybrid converter.

$$
\begin{gathered}
V_{C}=\frac{V_{O} \cdot n \cdot V_{i n}}{2 V_{i n}-V_{O} \cdot n} \\
V_{S-H}=V_{i n}+\frac{V_{O} \cdot n \cdot V_{i n}}{2 V_{\text {in }}-V_{O} \cdot n} \\
V_{S-P}=V_{\text {in }}+\frac{V_{O} \cdot n_{1} \cdot V_{i n}}{2 V_{\text {in }}-V_{O} \cdot n_{1}}
\end{gathered}
$$

\section{Voltage Stresses of the Diodes}

According to the determined turn ratio $\mathrm{n}$, the maximum duty cycle $D_{\max }$ and the output voltage Vo, the voltages across the diodes of the proposed hybrid converter can be derived in equations (12)-(14). The voltages across $\mathrm{D}_{1}$ and $\mathrm{D}_{3}$ of the parallel hybrid converter in Fig. 1(a) are similar to the voltages of $D_{2}$ and $D_{4}$ in equations (12) and (14) in the interval of $\left(n V o, \mathrm{~V}_{\text {in_max }}\right)$. However, their turns ratio should be
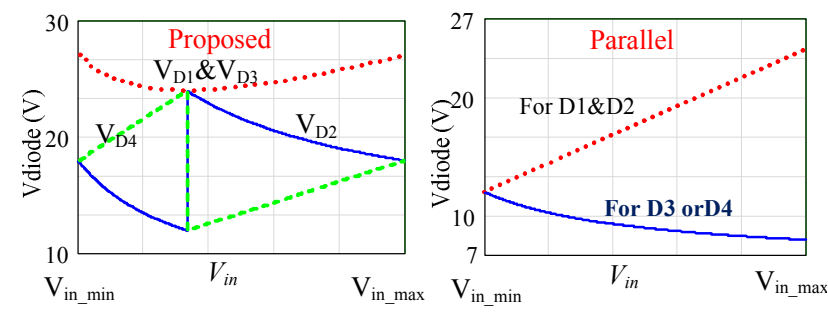

Fig. 9. Voltage stresses comparison among three rectifiers (from left to right: proposed, parallel hybrid and stacking hybrid).

substituted with $\mathrm{n}_{1}$ and voltage is in the whole range. The voltage stresses of the two converters are compared in Fig. 9.

$$
\begin{aligned}
& V_{D 1}=V_{D 3}=\frac{2 V_{i n}{ }^{2}}{2 n V_{i n}-n^{2} V_{O}} \\
& V_{D 2}= \begin{cases}\frac{2 V_{O} \cdot V_{i n}}{2 V_{i n}-n V_{O}} & \text { if }\left(n V_{O} \leq V_{i n} \leq V_{i n_{-} \max }\right) \\
\frac{V_{i n} V_{O}}{2 V_{i n}-n V_{O}} & \text { if }\left(V_{\text {in } n_{-} \min } \leq V_{\text {in }}<n V_{O}\right)\end{cases} \\
& V_{D 4}= \begin{cases}\frac{V_{\text {in }}}{n} & \text { if }\left(n V_{O} \leq V_{\text {in }} \leq V_{\text {in_max }_{-}}\right) \\
\frac{2 \cdot V_{\text {in }}}{n} & \text { if }\left(V_{\text {in_min }} \leq V_{\text {in }}<n V_{O}\right)\end{cases}
\end{aligned}
$$

\section{SIMULATIVE AND EXPERIMENTAL VERIFICATIONS}

A prototype of the proposed hybrid converter was built to verify the theoretical analysis. Based on the design considerations mentioned above, the key components are shown in Table I. Fig. 10 shows the schematics of the complete compensation circuit. Although the converter has two cases where input voltage varies, the compensation circuit can meet the regulation requirements in the whole input voltage range. This characteristic makes the design of the control loop easy. In order to verify the improvement of the proposed hybrid forward converter, a prototype of the parallel hybrid forward converter was also built. The input voltage is from $36 \mathrm{~V}$ to $72 \mathrm{~V}$ and the output is $12 \mathrm{~V} / 20 \mathrm{~A}$. The key parameters of the prototypes are listed in Table I.

The simulation results of the drive and the drain-to-source voltages are shown in Fig. 11. Fig. 12 shows the switching waveforms of the proposed converter at different input voltages. Fig. 12(a) shows the drive voltages and the drain to source voltages of the switches when $\mathrm{D}<0.5$ for the two phases, respectively. Fig. 12(b) shows the voltages of the same components when $\mathrm{D}>0.5$. The measured results are almost identical to the simulation results. ZVS on is achieved for all of the switches at different duty cycles because of the primary active clamp topology. The simulation results of the voltages across the transformer secondary windings and the rectifier's output voltage Vrec at different duty cycles are shown in Fig. 13. Fig. 14 shows the measured results for these voltages at different duty cycles. They are almost 


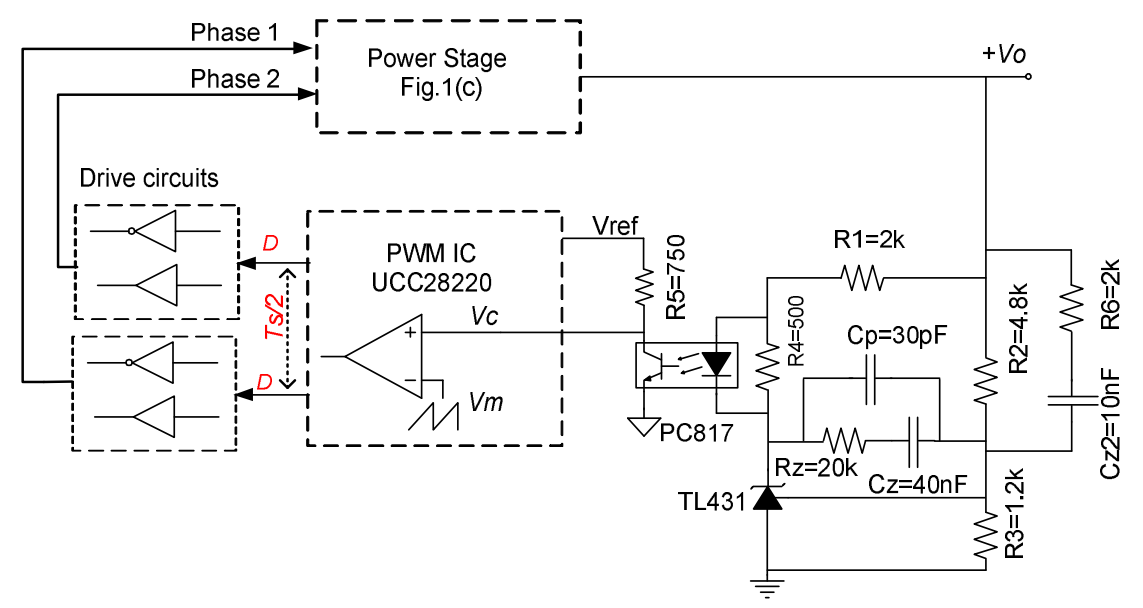

Fig. 10. Control scheme and compensation circuit of the proposed hybrid two-phase forward converter.

TABLE I

Key Components of the Proposed Converter And CONVENTIONAL CONVERTER

\begin{tabular}{|l|l|l|l|}
\hline \multicolumn{2}{|l|}{} & Proposed & Parallel rectifier \\
\hline \multicolumn{2}{|l|}{ Switches:Q1-Q4 } & IRF640 & IRF640 \\
\hline \multicolumn{2}{|l|}{ Rectifier diodes } & MBR3060 & MBR3060 \\
\hline $\begin{array}{l}\text { Transf } \\
\text { ormer }\end{array}$ & Core & PQ26/25(TP4A) & PQ26/25(TP4A) \\
\cline { 2 - 4 } & Turn ratio & $11: 3$ & $11: 4$ \\
\cline { 2 - 4 } & $\begin{array}{l}\text { Magnetizing } \\
\text { inductance }\end{array}$ & $0.29 \mathrm{mH}$ & $0.29 \mathrm{mH}$ \\
\hline Lo & $31 \mu \mathrm{H}$ & $75 \mathrm{uH}$ \\
\hline
\end{tabular}

identical to the theoretical waveforms in Fig. 3 and Fig. 4, respectively.

The voltages across diodes $\mathrm{D}_{1}-\mathrm{D}_{4}$ are shown in Fig. 15 and Fig. 16. The simulation results are shown in Fig. 15, and the measured results are in Fig. 16. It is obvious that when the duty cycle is about 0.5 , there is almost no current ripple in the inductor because $V_{R E C}$ is almost a DC voltage except for some spikes caused by a little asymmetry between the two phases. When the duty cycle (D) is higher than 0.5 , voltage $V_{\text {REC }}$ has a platform during the (1-D) interval, which increase the steady state gain.

It is verified that the proposed converter can work in different input voltage ranges with one compensation circuit. Fig. 17 shows the output voltage ripples at load steps between $75 \%$ to $25 \%$ full load. There is small difference in the overshoots of the output voltages between the different input voltages. This is caused by the different duty cycles and operating modes at different input voltages. However, it is acceptable with a compensation circuit for the proposed converter in the whole input voltage range.

The efficiencies under a full load for the two prototypes are

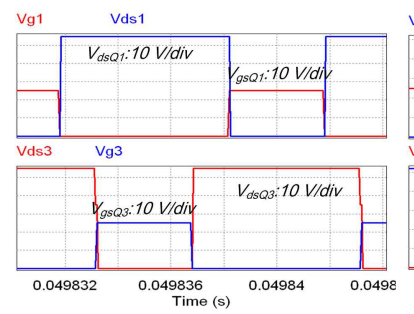

(a) $\mathrm{D}<0.5$.

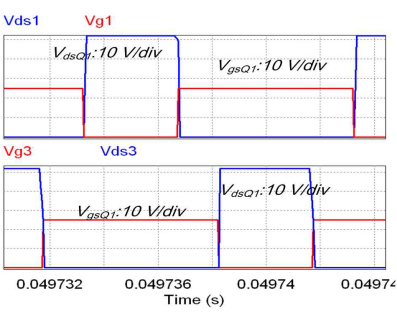

(b) $\mathrm{D}>0.5$.
Fig. 11. Simulation results of drive and $V d s$ waveforms of switches Q1 and Q2 at different duty cycles.

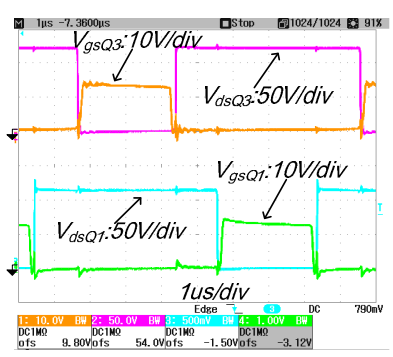

(a) $\mathrm{D}<0.5$.

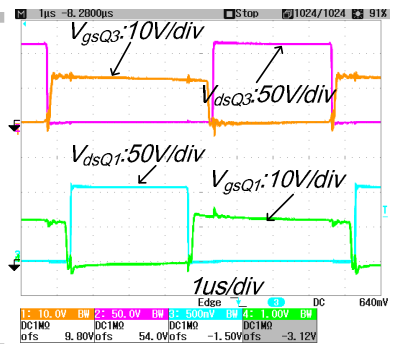

(b) $\mathrm{D}>0.5$
Fig. 12. Measured drive and $V d s$ waveforms of switches Q1 and Q2 at different duty cycles.

shown in Fig. 18. The efficiency improvement is about $1 \%$ for the proposed forward converter compared with the conventional parallel hybrid forward converter. The reduction in the conduction loss of the proposed converter is also verified in Fig. 19 especially under a heavy load. The efficiencies of the two prototypes are almost the same under a light load with different input voltages. With a load increase, the conduction loss increase in the parallel hybrid converter is higher than that of the proposed converter. Hence the efficiency of the conventional parallel hybrid converter is less than that of the proposed converter under a heavy load.

\section{CONCLUSIONS}




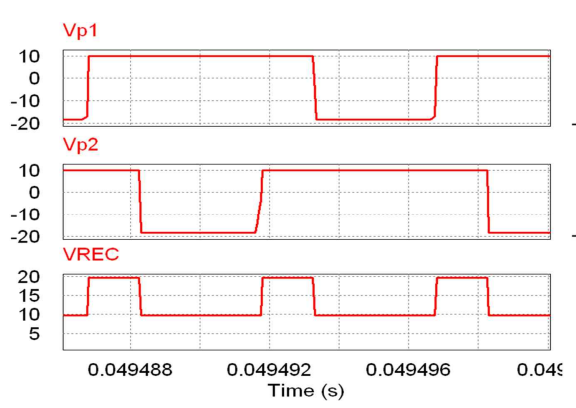

(a) $\mathrm{D}>0.5$.

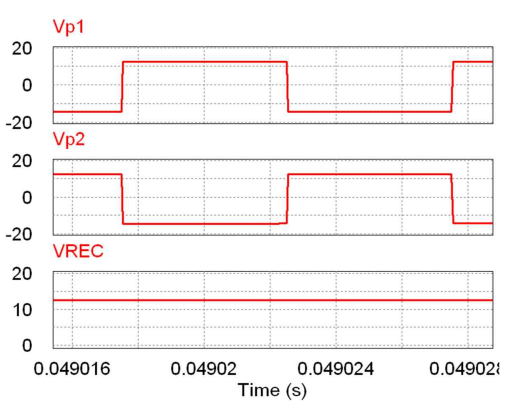

(b) $\mathrm{D}=0.5$.

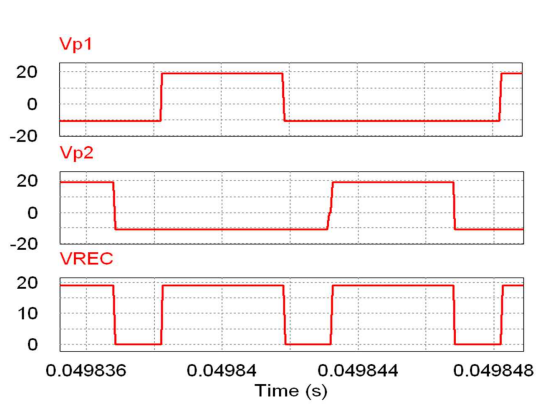

(c) $\mathrm{D}<0.5$

Fig. 13. Simulation results of voltages across secondary windings and of output voltage of rectifier at different duty cycles.

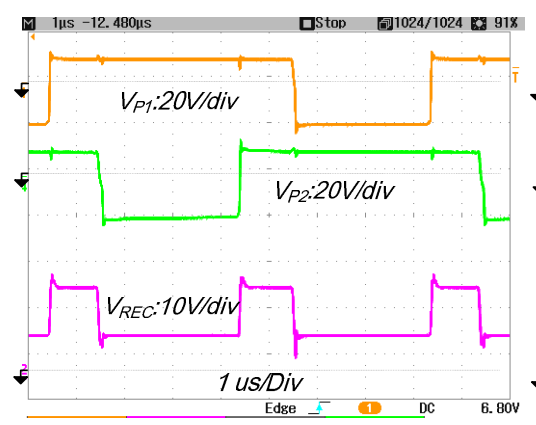

(a) $\mathrm{D}>0.5$.

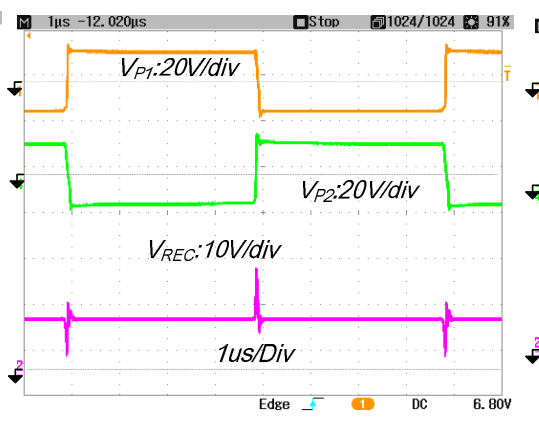

(b) $\mathrm{D}=0.5$.

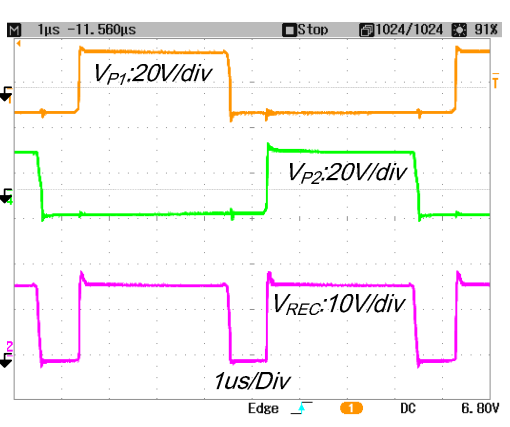

(c) $(\mathrm{D}<0.5)$.

Fig. 14. Measured voltages across secondary windings and of output voltage of rectifier at different duty cycles.

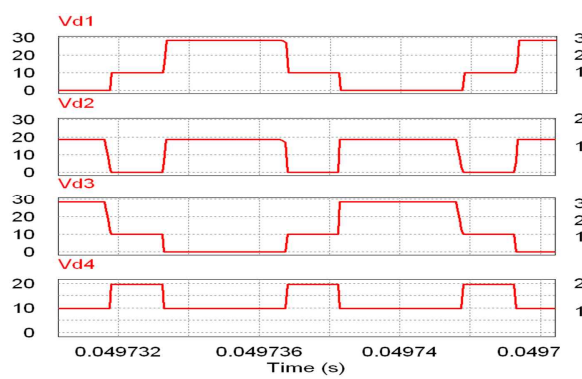

(a) $\mathrm{D}>0.5$.

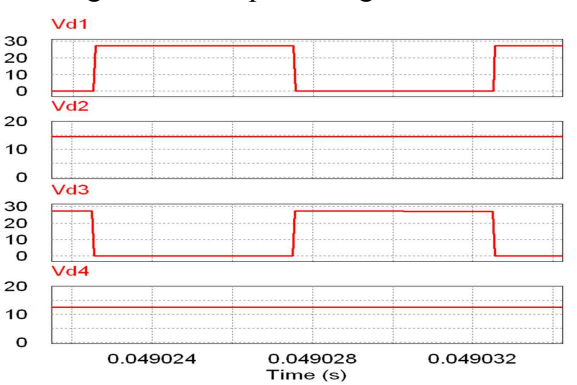

(b) $\mathrm{D}=0.5$.

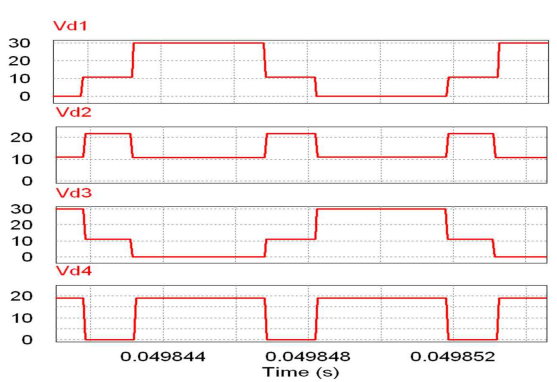

(c) $\mathrm{D}<0.5$.

Fig. 15. Simulated results of voltages across the diodes at different input voltages.

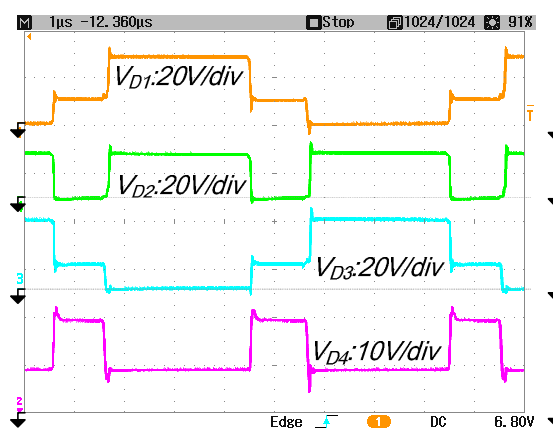

(a) $\mathrm{D}>0.5$.

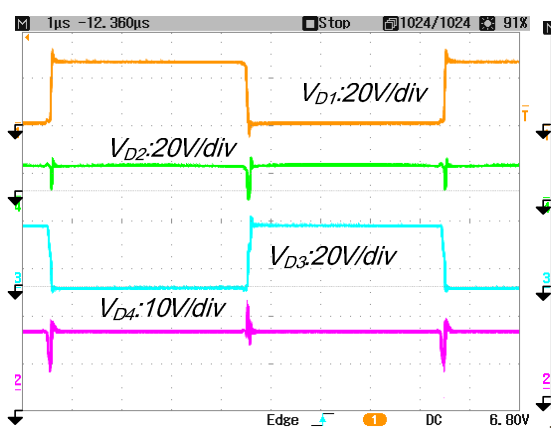

(b) $\mathrm{D}=0.5$.

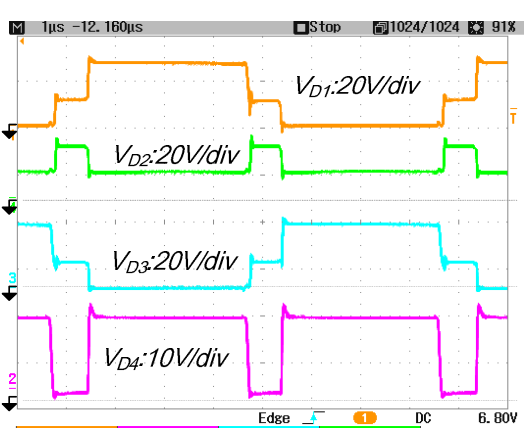

(c) $\mathrm{D}<0.5$.

Fig. 16. Measured voltages across the diodes $\mathrm{r}$ at different input voltages.

A two-phase hybrid active clamp forward converter with a hybrid HWR is proposed. The secondary side windings of the transformers can be auto-regulated between series and parallel conditions with pulse width modulation and interleaving control. With the hybrid rectifier, the conduction loss and the size of the filter of the proposed converter can be reduced when compared with those of the conventional parallel rectifier. Furthermore, with the series-parallel auto-regulated characteristic, the duty cycle can be extended and the ripple is less than that of the conventional parallel hybrid rectifier. Although the equivalent states of the hybrid rectifier are different in different duty cycle ranges, the steady 


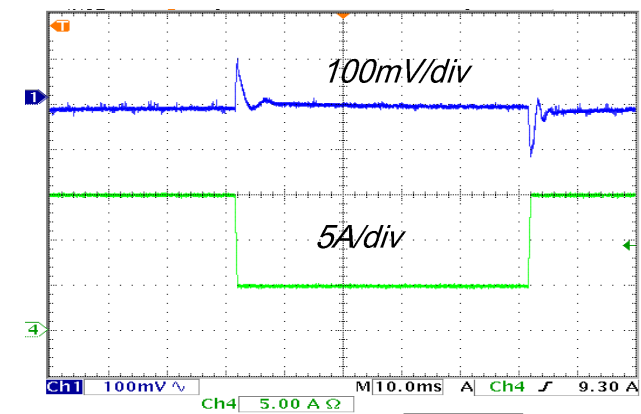

(a) $\mathrm{V}_{\mathrm{IN}}=44 \mathrm{~V}, \mathrm{D}>0.5$.

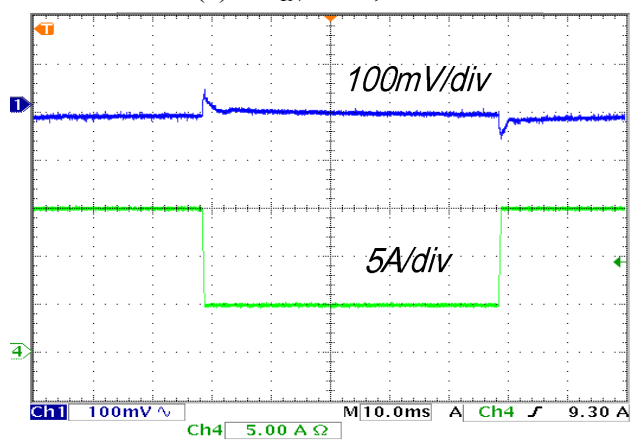

(b) $\mathrm{V}_{\text {IN }}=60 \mathrm{~V}, \mathrm{D}<0.5$.

Fig. 17. Measured output voltage ripple (upper) and current ripple (lower) at load transitions.

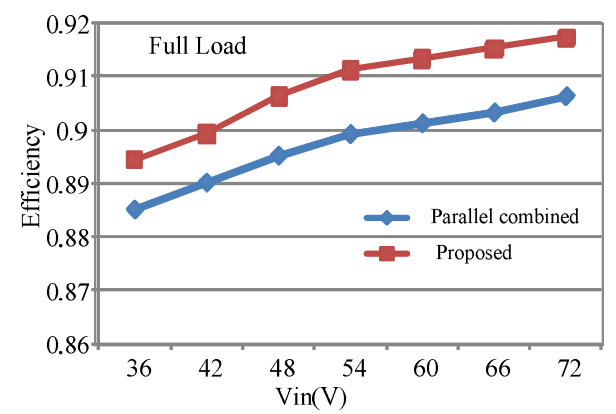

Fig. 18. Measured full load efficiencies at different input voltages for the proposed hybrid rectifier (Fig.1 (b )) and parallel hybrid rectifier (Fig. 1(a)).

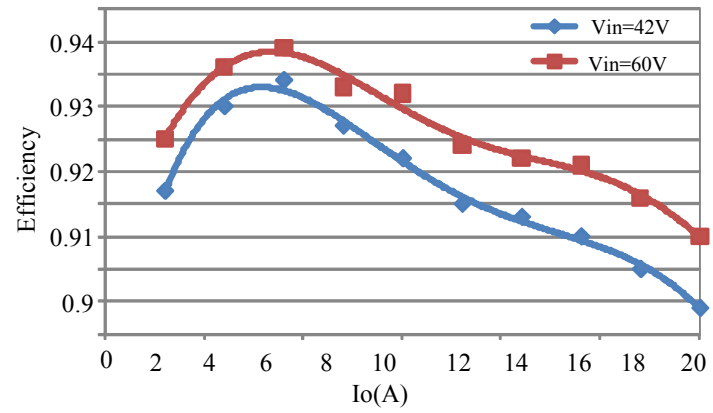

Fig. 19. measured efficiencies with different load currents and input voltages.

state gains are identical, which leads to a simple implementation of the compensation circuit for a closed loop. Experimental results verified the theoretical analysis, and the efficiency of the proposed converter can be improved. Its output inductance is much less than that of the parallel hybrid rectifier.

\section{ACKNOWLEDGMENT}

This work is support by National Natural Science Foundation of China under Grant 51007081 and 51277164, and Fundamental Research Funds for the Central Universities (No. 2013QNA4022).

\section{REFERENCES}

[1] T. Lequeu, G. Kalvelage, and P. Aubin, "An innovating topology of power converter: serial and parallel auto regulated configuration (SPARC)," IEEE Trans. Ind. Appl., Vol. 40, No. 3, pp. 632-641, Jun. 2004.

[2] X. Wu, J. Zhang, G. Wu, and Z. Qian, "High efficiency phase-shift controlled hybrid full bridge dc bus converter," in Proc. IEEE Applied Power Electronics Conference and Exposition (APEC), pp 1333-1338, 2006.

[3] X. Wu, W. Lu, J. Zhang, and Z. Qian, "Extra wide input voltage range and high efficiency DC-DC converter using hybrid modulation," in Proc. IEEE 41st Annual Industry Applications Conference (IAS), pp. 588-594. 2006.

[4] X. Wang, F. Tian, and I. Batarseh, "High efficiency parallel post regulator for wide range input DC-DC converter," IEEE Trans. Power Electron., Vol. 23, No. 2, pp 852-857, Mar. 2008.

[5] K. Jin and X. Ruan, "Hybrid full-bridge three-level LLC resonant converter- A novel DC-DC converter suitable for fuel-cell power system," IEEE Trans. Ind. Electron., Vol. 53, No. 5, pp. 1492-1503, Oct. 2006.

[6] X. Ruan, Z. Chen, and W. Chen, "Zero-voltage-switching PWM hybrid full-bridge three-level converter," IEEE Trans. Power Electron., Vol. 20, No. 2, pp. 395-404, Mar. 2005.

[7] F. D. Tan, "The forward converter: from the classic to the contemporary," In Proc. IEEE Applied Power Electronics Conference and Exposition, (APEC), pp. 857-863, 2002.

[8] C. D. Bridge, "Clamp voltage analysis for RCD forward converters," in Proc. Applied Power Electronics Conference and Exposition, (APEC), pp. 959-965, 2000.

[9] Y.-K. Lo, T.-S. Kao, and J.-Y. Lin, "Analysis and design of an interleaved active-clamping forward converter," IEEE Trans. Ind. Electron., Vol. 54, No. 4, pp. 2323-2332. Aug. 2007.

[10]J. Zhao, M. Sekine, S. Ushiki, T. Sato, T. Nabeshima, and T. Nakano, "An improved interleaved forward converter," in Proc. IEEE PESC, pp. 1-5. 2006.

[11] T. Jin, W. Zhang, A. Azzolini, and K. M. Smedley, "A new interleaved series input parallel output (isipo) forward converter with inherent demagnetizing features," IEEE Trans. Power Electron., Vol. 23, No. 2, pp. 888-895, Mar. 2008.

[12] M. T. Zhang, M. M. Jovanovic, and F.C Lee, "Analysis and evaluation of interleaving techniques in forward converters," IEEE Trans. Power Electron., Vol. 13, No. 4, pp. 690-698, Jul. 1998.

[13] T. Qian and B. Lehman, "Dual interleaved active-clamp forward with automatic charge balance regulation for high input voltage application," IEEE Trans. Power Electron., Vol. 23, No. 1, pp. 38-44, Jan. 2008.

[14] K.-B. Park, C.-E. Kim, G.-W. Moon, and M.-J. Youn, "Interleaved forward converter for high input voltage 
application with common active-clamp circuit and series rectifier," in Proc. Applied Power Electronics Conference and Exposition (APEC), pp. 1440-1445, 2009.

[15] G. Zhang, X. Wu, W. Yuan, J. Zhang, and Z. Qian, “A new interleaved active-clamp forward converter with parallel input and series-parallel output," in Proc. Applied Power Electronics Conference and Exposition (APEC), pp. 40-44. 2009.

[16] R. T. Bascope and I. Barbi, "A double ZVS-PWM active-clamping forward converter," in Proc. IEEE Applied Power Electronics Conference, pp. 596-601. 1999.

[17] B.-R. Lin, C. E. Huang, and D. Wang "Analysis and implementation of a zero-voltage switching forward converter with a synchronous rectifier," IEE Proc.-Electr. Power Appl., Vol. 152, No. 5, pp.1085-1092. Sep. 2005.

[18] Q. M. Li and F. C. Lee "Design consideration of the active-clamp forward converter with current mode control during large-signal transient," IEEE Trans. Power Electron. Vol. 18, No. 4,.pp. 958-965, Aug. 2003.

[19] Y. Panov and M. M. Jovanovic "Small-signal analysis and control design of isolated power supplied with opto-coupler feedback," IEEE Trans. Power Electron., Vol. 20, No. 4, pp. 823-832, Jul. 2005.

[20] H.-f. Wu and Y. Xing, "A family of forward converters with inherent demagnetizing features based on basic forward cells," IEEE Trans. Power Electron., Vol. 24, No. 11, pp. 2828-2834, Nov. 2010.

[21] B.-R. Lin, K. Huang, and D. Wang, "Analysis, design, and implementation of an active clamp forward converter with synchronous rectifier," IEEE Trans. Circuits Syst. I, Reg. Papers, Vol. 53, No. 6, pp. 1310-1319, Jun. 2006.

[22] B. Zhao, M. Sekine, S. Ushiki, T. Sato, T. Nabeshima, and T. Nakano, "An improved interleaved forward converter," in Proc. IEEE PESC, pp. 1-5. 2006.

[23] Y. Panov and M. M. Jovanovic, "Small-signal analysis and control design of isolated power supplied with opto-coupler feedback," IEEE Trans. Power Electron., Vol. 20, No. 4, pp. 82-832, Jul. 2005.

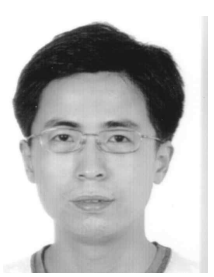

Xinke Wu received his B.S. and M.S. in Electrical Engineering from the Harbin Institute of Technology, Harbin, China, in 2000 and 2002, respectively. He received his $\mathrm{Ph} . \mathrm{D}$. in Electrical Engineering from Zhejiang University, Hangzhou, China, in 2006. He was a Postdoctoral Fellow at the National Engineering Research Center (NERC) for Applied Power Electronics at Zhejiang University from 2007 to 2009, and he was an Assistant Research Fellow from 2009 to 2010. From 2011 to 2012, he was a Visiting Scholar in the Center of Power Electronics System (CPES), Virginia Tech, Blacksburg, VA. Since 2011, he has been an Associate Professor in Electrical Engineering at Zhejiang University. His current research interests include high efficiency LED driving technology, soft switching and high efficiency power conversions, and power electronics systems integration. $\mathrm{Dr}$. $\mathrm{Wu}$ received the Distinguished Young Scholar Award of Zhejiang University in 2012.

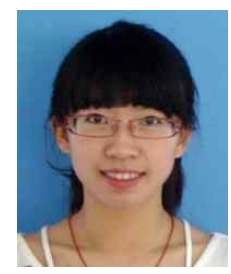

Hui Chen was born in China, in 1988. She received her B.S. from Zhejiang University, Hangzhou, China, in 2010. She is currently working toward her Ph.D. in the College of Electrical Engineering, Zhejiang University. Her current research interests include high efficiency dc-dc converters and topology research. 